\title{
La prensa en modo pandemia: una aproximación a las agendas informativas de Expreso y EI País sobre COVID-19
}

\section{The press in pandemic mode: an approach to the information agendas of Expreso and EI País on COVID-19}

\author{
Jorge Manrique-Grisalesa \\ a Doctorado Interuniversitario en Comunicación, Universidad de Huelva, España
}

\section{Resumen}

Introducción: EI COVID-19 modificó radicalmente las agendas informativas de los medios de comunicación, considerando el vuelco que provocó en la economía global y la cotidianidad de las personas. En este contexto, los medios han sido referentes en la construcción de la realidad y la información pública durante la pandemia. Objetivos: La presente investigación identificó los personajes, instituciones, territorios, temas, controversias y estilos de vida asociados a la pandemia del COVID-19, revelados a través de los contenidos de dos medios de comunicación de Ecuador y Colombia. Metodología: Empleando el Método Histórico-Discursivo (MHD), se analizaron los artículos sobre COVID-19 publicados en la versión digital de los periódicos Expreso, de Guayaquil (Ecuador), y El País, de Cali (Colombia) durante los meses de marzo y abril de 2020. Resultados: El análisis reveló las tensiones entre el ejercicio político y las prioridades sanitarias. Se denota que los alcaldes de Guayaquil y Cali fueron el foco de la información, y que se priorizaron los datos epidemiológicos y la información sobre medidas sanitarias. Conclusión: Nuestro estudio estableció que el cubrimiento sobre el COVID-19 enfocado en los datos de la pandemia, no contribuyó a que los ciudadanos asimilaran el riesgo de la enfermedad, y a que mantuvieran estilos de vida que hicieron que el número de contagios creciera de forma exponencial.

Palabras clave: COVID-19; comunicación y salud; agenda Setting; Newsmaking; Método Histórico Discursivo.

\begin{abstract}
Introduction: COVID-19 radically changed the media's information agendas, considering the turnaround it caused in the global economy and people's daily lives. In this context, the media has been a reference in the construction of reality and public information during the pandemic. Objectives: This research identified the characters, institutions, territories, topics, controversies and lifestyles associated with the COVID-19 pandemic, revealed through the contents of two media in Ecuador and Colombia. Methodology: Using the Historical-Discursive Method (MHD), we analyzed the articles on COVID-19 published in the digital version of the newspapers Expreso, from Guayaquil (Ecuador), and El País, from Cali (Colombia) during the months of March and April 2020. Results: The analysis revealed the tensions between the political exercise and health priorities. It shows that the mayors of Guayaquil and Cali were the focus of the information, and that epidemiological data and information on health measures were prioritized. Conclusion: Our study established that coverage of COVID-19 focused on pandemic data did not contribute to citizens assimilating the risk of the disease, and maintaining lifestyles that caused the number of infections to grow exponentially.
\end{abstract}

Keywords: COVID-19; communication and health; agenda Setting; Newsmaking; Historical Discursive Method. 


\section{Introducción}

L

a realidad está constituida por los millones de sucesos que tienen lugar cada día alrededor del mundo. El trabajo de los periodistas e informadores es transformar una parte de esos sucesos en acontecimientos (Tuchman, 1983) y recrear la realidad a través de un proceso más complejo de lo que revela un titular o un lead. En este contexto, a su vez, los medios de comunicación moldean la percepción del público sobre asuntos de interés común (Califano, 2015). En la actualidad, las prácticas que llevan a cabo los medios para influenciar al público pueden agruparse bajo el concepto de agenda Setting (McCombs \& Shaw, 1972).

Las representaciones sociales sobre las enfermedades (Eicher \& Bangerter, 2015; Eslava Albarracín \& Puntel de Almeida, 2002, Idoiaga Mondragon, Gil de Montes, \& Valencia, 2017), especialmente cuando se convierten en epidemias o pandemias, marcan la agenda de los medios (Idoiaga Mondragon, Gil de Montes, \& Valencia, 2018). El interés público en la salud se remonta a la antigüedad desde episodios como la extraña muerte de Alejandro Magno (García Gual, 2012), o los registros de la primera epidemia importada desde España a través de los cerdos que trajo Colón en su segundo viaje al nuevo continente (Muñoz-Sanz, 2006; Cordero del Campillo, 2001). Más recientemente, patologías como el $\mathrm{VIH}$ han sido objeto de análisis desde la perspectiva de los medios de comunicación, y desde escenarios que evalúan de qué manera los medios han influido en la percepción pública de la enfermedad (Garabato González, 2002; Martín, Doblas, Cerdà, \& Danet, 2014; Martín Lahuerta, 2006). El cubrimiento mediático de temas de salud se relaciona no sólo con el creciente interés en nuevas patologías como el COVID-19, sino también con los avances científicos en materia de tratamientos médicos o los hábitos de vida saludables. De esta manera, la salud surge como un tema de interés público en la agenda mediática del siglo XXI (Serrano Villalobos, 2018).

Al momento de la realización de este estudio, el coronavirus SRAS-CoV-2 o COVID-19 afecta a 4.523.916 personas en 188 países del mundo (Johns Hopkins University, 2020). Desde comienzos de 2020, los medios cambiaron sus portadas y titulares para cubrir la que es hasta ahora la noticia más importante del siglo XXI. Sin embargo, los periodistas tuvieron que desplazarse al frente informativo con un contexto limitado y sin los conocimientos relevantes para desarrollar la tarea de informar.
El presente estudio se propuso establecer los personajes, instituciones, territorios, temas, controversias y estilos de vida en las ciudades de Guayaquil (Ecuador) y Cali (Colombia) revelados a través de los medios de referencia durante la pandemia del COVID-19. Se realizó, desde el punto de vista metodológico, una aproximación a la agenda Setting (McCombs \& Shaw, 1972; McCombs, 1992; McCombs, 2015; Funk \& McCombs, 2017; Aruguete, 2017) y al Newsmaking (Tuchman, 1983; Verón, 1987; Charaudeau, 2003; Shoemaker \& D. Reese, 1996) de los periódicos Expreso de Guayaquil y El País de Cali para establecer las categorías de análisis que conforman el Método Histórico-Discursivo (MHD). Esta investigación permitió observar los acentos que cada medio le dio a la construcción social de la realidad posicionando determinados temas bajo la premisa fundante de la prensa de privilegiar el "bien común". Nuestros resultados revelan que Expreso y El País se enfocaron en el reporte de datos oficiales y medidas sanitarias, dejando de lado el análisis de las situaciones que más afectan a la vida de los ciudadanos.

\section{Marco contextual: relatos de la gripe en Ecuador y Colombia}

\section{La gripe que llegó a América con Cristóbal Colón}

El continente americano vivió en aislamiento por miles de años con respecto a Euroasia y África. En el siglo XV, con la llegada de personas, animales y plantas procedentes de España, se produjo un impacto sustancial en el medio ambiente y la salubridad del nuevo continente (Cordero del Campillo, 2001).

Con el segundo viaje de Colón a América, en 1493, la gripe comenzó a ser noticia en esta parte del mundo. A La Isabela (hoy Santo Domingo) llegaron 17 naves con 1.500 hombres y algunos animales domésticos como caballos, vacunos, gallinas, ovejas, cabras y cerdos; al igual que semillas de trigo y cebada (Muñoz-Sanz, 2006; Cordero del Campillo, 2001). El navegante y amigo de Colón, Michel de Cuneo, reportó la prosperidad de los animales domésticos traídos por los españoles a las Antillas gracias a la amplia variedad de árboles y frutos disponibles para su alimentación (Colón et al., 2005).

Se calcula que entre 1517 y 1600 llegaron a las Indias 21.365 españoles. También llegó un número importante de negros africanos esclavizados para reemplazar la mano de obra indígena en las islas del Caribe. Se estima que los cerdos fueron la fuente de un tipo de influenza 
desconocido localmente (Manrique, Martínez, Meléndez, \& Ospina, 2009). El médico Diego Álvarez Chanca, quien viajó con Colón en 1493, advirtió que la gripe afectaba en mayor medida a los indios que a los españoles. El encuentro entre europeos y americanos "supuso el intercambio de agentes patógenos nuevos para uno y otro grupo étnico, y las enfermedades cursaban de modo distinto en unos u otros, en armonía con la existencia o carencia de experiencia inmunitaria previa" (Cordero del Campillo, 2001, p. 602). De acuerdo con los cronistas de Indias como Fray Bartolomé de las Casas, la influenza (probablemente tipo A) traída por los conquistadores provocó una reducción sustancial de la población indígena.

\section{La "gripe española" en Ecuador y Colombia}

Siglos más tarde, el 13 de diciembre de 1918, se documentó en Guayaquil el primer caso de la llamada "gripe española", nombre que se le dio a la patología por su difusión en la prensa de España. Se trataba de un patógeno que se propagó de manera letal e incontrolable hasta convertirse en pandemia a finales de la Primera Guerra Mundial. Se estima que la enfermedad llegó al puerto ecuatoriano desde Lima, probablemente con un viajero (Rodas Chaves, 2015; Rodas Chaves, 2018).

Al comienzo, la situación no causó alarma, pues se tenía noticia que la enfermedad afectaría especialmente a la población ubicada en climas de montaña. Las principales fuentes informativas sobre la pandemia se centraron en el diario $A B C$ de Madrid y el periódico norteamericano The Evening World (Rodas Chaves, 2018). El 16 de diciembre la "gripe española" se detectó en Quito, ubicada a 2.700 metros sobre el nivel del mar. En ese momento, las autoridades suspendieron todo tipo de actividades públicas y académicas. En enero de 1919, los medios oficiales reportaron que la enfermedad había contagiado a 15.070 personas y causado la muerte de 185 en la ciudad de Quito.

Al mismo tiempo, la "gripe española" entró a Colombia por el puerto de Barranquilla y cobró su mayor número de víctimas en el altiplano cundiboyacense, donde factores como la altura sobre el nivel del mar, la pobreza y el hacinamiento aumentaron la letalidad del patógeno (Manrique, Martínez, Meléndez, y Ospina, 2009). En 1918 Colombia era un país mayoritariamente rural, donde el $75 \%$ de la población vivía por fuera de las cabeceras municipales (La Rosa \& Mejía, 2017). La cobertura de servicios públicos era deficienteasí comolas condiciones higiénicas. La gripe entró por la costa norte y luego pasó a Bogotá, donde se calcula que contagió a unas 100.000 personas (cerca del 80 por ciento de la población) entre octubre y noviembre de 1918. La situación alteró la cotidianidad de la capital colombiana: "Las oficinas públicas, los colegios, la universidad, las chicherías, los teatros y las iglesias estaban vacías; los servicios urbanos colapsaron; la policía, el tranvía, el tren y los correos se paralizaron porque la mayoría de policías, operarios, curas, alumnos y profesores y empleados enfermaron" (Carvajal Estupiñán, Martínez Martín, Meléndez Álvarez, \& Manrique, 2006, p. 25).

Entre tanto, el periódico El Relator reportó las muertes ocasionadas por la pandemia entre octubre y diciembre de 1918 en Cali y varios municipios del departamento del Valle del Cauca, en el suroccidente del país: "Parece, según los datos oficiales de la Dirección de Higiene, que la epidemia de la gripa toma proporciones mayores y por lo tanto invade la ciudad, especialmente en las habitaciones de las clases pobres" (El Relator, 1918), se lee en uno de los encabezados publicados el miércoles 18 de diciembre de 1918. En tono más alarmante, el párroco de Sevilla, Valle, escribe: "Epidemia implacable; recursos agotados; invoco caridad socorrer numerosos infelices. Ayer ocho defunciones" (El Relator, 1918).También se solicita que el Concejo Municipal de Cali apruebe los recursos necesarios para afrontar la emergencia sanitaria. El martes 24 de diciembre El Relator informa que en Cali y sus alrededores el número de enfermos es mayor a 5.000. De igual forma, el periódico promocionaba medicamentos y productos para combatir la gripe que podían adquirirse en las farmacias de la ciudad (Ver Figura No. 1). También aparecen avisos y notas patrocinadas del "Jabón líquido medicinal", el jarabe "Anti-tísico" y el "Jarabe de Higos de California".

El hecho de que las enfermedades viajan de un país a otro o de un continente a otro se evidenció más fuertemente con el incremento de los viajes y la modernización de los medios de transporte y a pesar de que no se tenían los recursos para hacerle seguimiento a las patologías, desde la prensa comenzaron a etiquetarse las epidemias del siglo XX por su lugar de origen, por los sitios donde causaron más estragos 0 , como en el caso de la "gripe española", donde se le dio más difusión en los medios. 


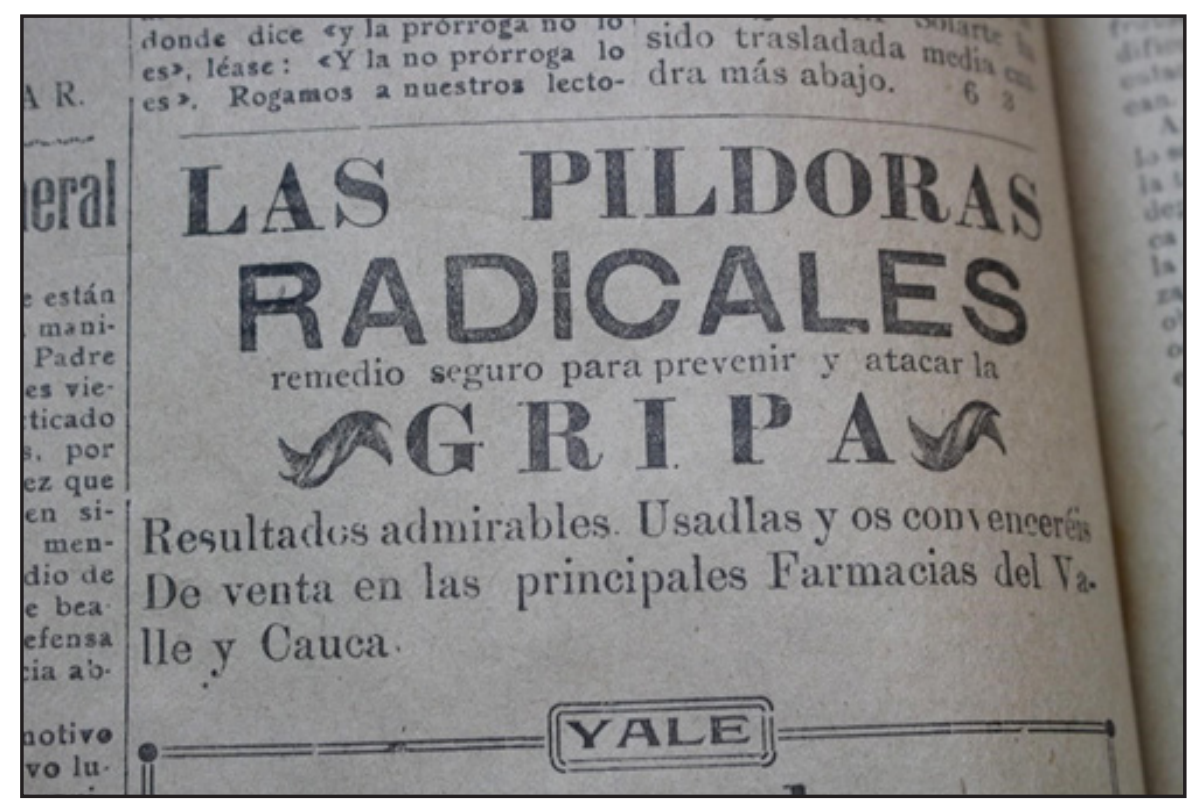

Figura 1. Aviso publicado por El Relator el 18 de diciembre de 1918. En el aviso se promociona un producto para curar la "gripe española". El nombre del producto tiene tinte político teniendo en cuenta la ideología liberal del periódico y el hecho de que Colombia venía siendo gobernada por sucesivos presidentes conservadores. Foto Jorge ManriqueGrisales.

\section{Del A H1N1 al COVID 19}

El 15 de mayo de 2009, la ministra de Salud de Ecuador, Caroline Chang, informó oficialmente del primer caso de Influenza A H1N1 en un niño que llegó a Guayaquil procedente de Estados Unidos (OPS, 2009). Se trataba de un nuevo virus de procedencia porcina y capaz de infectar a los humanos, que se originó en Estados Unidos y México (Toral Cáceres, Rodríguez Bajaña, \& Clery Aguirre, 2014). La alerta creció el 20 de mayo del mismo año cuando se confirmaron seis nuevos casos en Guayaquil y uno en Quito. Esto hizo que se suspendieran las clases en cuatro colegios del puerto ecuatoriano como medida preventiva. El 11 de junio el Ministerio de Salud reveló que en la provincia de Guayas el número de infectados llegaba a 59 , a los que sumaron otros de Quito (7), Machala (3), Manta (1) y Cuenca (3) para un total de 73 casos (OPS, 2009). En abril de 2010 la cifra en Ecuador llegaba a 2.251 casos y 129 muertes.

En Colombia, la denominada "gripe porcina" contagio a 8 de cada 100.000 habitantes, especialmente en las grandes ciudades. Los grupos poblacionales más afectados fueron los de 0 a $9 ; 20$ a 39 y 45 a 54 años, al igual que se observó una mayor incidencia en las mujeres entre los 25 y 29 años (Álvarez, 2010). El entonces ministro de Protección de Colombia, Diego Palacios, anunció la creación de una "sala de crisis" para monitorear los centros hospitalarios del país y anunció la adquisición de 200.000 tratamientos antivirales (El Tiempo, 2009). El pico de la enfermedad se alcanzó entre los meses de agosto y septiembre de acuerdo con los datos procesados por el Sistema de Nacional de Vigilancia en Salud Pública (Sivigila). Ante la percepción de riesgo e incertidumbre en la población, expertos y autoridades mundiales en el tema comenzaron a aparecer en los medios de comunicación (Mondragón Pérez, Hermelin, \& Moreno Londoño, 2013; Coronado Robles, CatalánMatamoros, \& Martínez González, 2016).

De acuerdo con una encuesta a nivel latinoamericano de la consultora Livra citada en Mondragón Pérez et al. (2013), el 34,9\% de los colombianos dijeron sentirse amenazados de contraer gripe durante la pandemia de A H1N1. Esta cifra contrasta con México, donde comenzó el brote, con apenas un 21,3\% de ciudadanos temerosos de contagiarse. Finalizando 2009 y a medida que fue disminuyendo la tasa de contagios del virus A H1N1, también disminuyó la cobertura periodística. De acuerdo con las cifras oficiales, en Colombia se registraron 272 muertes a causa del virus $\mathrm{AH} 1 \mathrm{~N} 1$ entre 2009 y 2010. La enfermedad fue considerada como la primera pandemia del siglo XXI por la Organización Mundial de la Salud (OMS).

Diez años después de este incidente, el 31 de diciembre de 2019, fue notificada oficialmente la aparición del coronavirus SRAS-CoV-2 COVID-19. El brote infeccioso tuvo su origen en la provincia de Wuhan, en China (Singer, 2020). La OMS declaró estado de 
pandemia el 11 de marzo de 2020, en momentos en que la enfermedad presentaba 118.000 casos en 114 países y había provocado la muerte de 4.291 personas (OMS, 2020). La pandemia del COVID-19 provocó la aparición de temas de salud en las portadas de los periódicos debido al interés por los hábitos de vida saludables y también como una demanda permanente por la cobertura de servicios básicos en la población más vulnerable (Salgado Ramos, Duro Mota, López Moyano, \& Muñoz-Delgado Buchó, 2005). Una encuesta del Centro Nacional de Consultoría de Colombia reveló el 30 de marzo de 2020 que seis de cada 10 colombianos cree que es "muy probable" que se pueda contagiar con el coronavirus (El Tiempo, 2020).

Desde el reporte del primer caso de COVID-19 en Guayaquil, el 29 de febrero de 2020, hasta el 13 de abril del mismo año, la provincia de Guayas acumulaba un total de 10.878 casos y 1.614 muertos, de acuerdo con las cifras del Ministerio de Salud del Ecuador (Ministerio de Salud de Ecuador, 2020). En Cali y el Valle del Cauca, entre el 15 de marzo y el 13 de abril se registraron 498 casos y 13 fallecidos (El País, 2020d).

Con la aparición de nuevas epidemias, los medios no sólo cumplen el papel de termómetro para medir los impactos en la opinión pública, sino que también podrían desempeñar una tarea educativa (Stoian, 2019) en la medida en que tienen la capacidad de orientar, concientizar y ayudar de alguna forma en la profilaxis de las patologías acerca de las que se informa.

\section{Marco teórico}

El presente estudio articula dos teorías para el análisis de los medios de información: la agenda Setting y el Newsmaking. De las muchas aproximaciones al concepto de agenda Setting, McCombs (2009) (citado por Guzmán \& Martínez Prediger, 2010), precisa que hay dos que pueden considerarse correctas: la primera se refiere a la transferencia de la prominencia de la agenda de los medios a la agenda pública, mientras que la segunda señala más puntualmente cómo "los elementos prominentes en la agenda de los medios frecuentemente se convierten en prominentes en la agenda pública" (p.19). Por su parte, Bernard Cohen consideró que "la prensa quizá en muchas ocasiones no consiga decirle a la gente qué pensar, pero es asombrosamente exitosa en decirle a sus lectores sobre qué pensar" (Guzmán \& Martínez Prediger, 2010, pp. 17-18).

McCombs (1992) propuso un modelo de agenda Setting basado en la metáfora de las capas de una cebolla. De afuera hacia dentro, la primera capa, denominada agenda Setter, corresponde a los "hacedores de la información externos al medio" como presidentes, partidos políticos, instituciones oficiales y las empresas. En la segunda capa "se encuentran los propios medios de comunicación, que se influyen unos a otros" y comparten agendas. En la tercera capa figuran "los soportes técnicos para la producción mediática". La cuarta capa incluye la "cultura organizacional del medio". La quinta se relaciona con "las preferencias individuales de los periodistas y sus posiciones ideológicas", mientras que en el corazón de la cebolla se ubican "los estilos 0 géneros periodísticos" (Aruguete, 2017, pp. 40-41).

En segundo lugar, la teoría del Newsmaking (Tuchman, 1983; Verón, 1987; Shoemaker y Reese, 1996) pretende explicar la forma como se construye la realidad social (Berger \& Luckmann, 2001) desde las noticias. Los hechos se convierten en acontecimiento cuando algo rompe con la cotidianidad (Charaudeau, 2003). Verón (1987), por su parte, propuso niveles para medir la intencionalidad de los discursos de la prensa en la tarea de contar la realidad dibujada en los acontecimientos. En dichos niveles se pasa de los datos básicos de la información (qué, quién cómo, cúando y dónde) o género seco (Bastenier, 2001) a la interpretación, la valoración, la postura y la exhortación.

Con base en las teorías de agenda Setting y Newsmaking, y tomando como referencia el modelo de la cebolla, el presente estudio establece tres capas de análisis: la externa (agenda Setter), una intermedia donde se integran varios elementos de la agenda Setting propiamente dicha, y una interna que recoge tres niveles discursivos (datos, interpretación y valoración) con las que se puede ver más claramente cómo los medios construyen agendas informativas que determinan su influencia en la sociedad y les permiten seleccionar ese trozo de realidad del que se ocupan en su quehacer diario. Un examen de los acontecimientos registrados en las versiones digitales de los diarios Expreso, de Guayaquil, y El País, de Cali, puede revelar un retrato de esas sociedades sin que éste necesariamente corresponda a todas las miradas que puedan darse sobre un determinado periodo histórico. Siempre será una imagen incompleta, pero al fin y al cabo una imagen, tal como dijo Walter Lippman en 1922 en su libro Opinión Pública: "los medios crean imágenes e impresiones del mundo exterior en nuestras mentes" (Guzmán \& Martínez Prediger, 2010, p.18).

Tuchman (1983) considera que la noticia es "primero y primordialmente una institución social" (p. 16) aliada de las instituciones legitimadas y por ende defensora del status quo. Los medios crean clasificaciones de los sucesos noticiables y "estas clasificaciones influyen en la 
asignación de la cualidad de noticiabilidad a los sucesos" (p. 25).

La visión de la prensa desde las agendas mediáticas puede revelar los entresijos de una serie de decisiones que determinan lo que se publica 0 no se publica. Aquí entran en juego las fuentes, el tratamiento de los hechos, los intereses de diversos actores sociales, las formas como se comunican los acontecimientos y los imaginarios sociales que se construyen alrededor de los hechos registrados como noticia.

Para Martini (2007):

Esta naturalización de un discurso sobre el mundo se basa en un acuerdo $o$ un consenso (real o aparente) acerca de la realidad, de los imaginarios sobre la sociedad y sobre el propio trabajo y de los valores, que hace a la selección y clasificación de la información y a las maneras en que se la interpreta y se construyen las agendas y las noticias (Martini, 2007, p.79).

\section{Objetivos}

Nuestro objetivo fue identificar los personajes, instituciones, territorios, temas, controversias y estilos de vida asociados a la pandemia del COVID-19, revelados a través de los contenidos de dos medios de comunicación de Ecuador y Colombia.

\section{Metodología}

Para este fin, se evaluaron las versiones digitales de los periódicos Expreso de Guayaquil (Ecuador) y El País de Cali (Colombia), considerando que ambas ciudades tienen una población similar y sobresalen por su número de contagios, siendo Guayaquil la primera de Ecuador, y Cali la segunda en Colombia después de Bogotá.

\section{Selección de la información}

Se analizaron los artículos periodísticos de Expreso.ec y Elpais.com.co publicados entre el 29 de febrero y el 13 de abril de 2020, período que comprende la aparición de los primeros casos de COVID-19 en ambas ciudades (Guayaquil el 29 de febrero y Cali el 15 de marzo) y las primeras medidas de aislamiento decretadas por los gobiernos de Ecuador y Colombia.

Las piezas informativas se tomaron de las portadas virtuales de ambos periódicos empleando Wayback Machine $®$, una aplicación que permite acceder a versiones de cualquier portal web en una fecha estipulada. Se seleccionaron los artículos relacionados con Guayaquil y Cali, sus áreas metropolitanas y la provincia (Guayas en el caso de Ecuador) y el departamento (Valle del Cauca en el caso de Colombia) y que cumplieran al menos uno de los siguientes criterios: 1) Estar relacionado con el COVID-19 y la ciudad, incluidos los primeros casos, 2) Hacer referencia a medidas tomadas por los gobiernos locales para enfrentar la pandemia, 3) Registrar actividades restringidas por las cuarentenas (educación, comercio, entretenimiento, cultura, deporte, turismo y movilidad), 4) Reseñar voces de expertos en distintas disciplinas, 5) Reseñar historias de sobrevivientes, 6) Referir aspectos de infraestructura en salud, insumos y tratamientos médicos para atender la pandemia, y 7) Relatar aspectos del aprovisionamiento de víveres y medicinas por parte de las familias durante la cuarentena. En total se recuperaron y analizaron 173 artículos de Expreso de Guayaquil, y 180 de El País de Cali.

\section{Análisis de la información}

El análisis de las piezas informativas recuperadas se llevó a cabo empleando el Método HistóricoDiscursivo (MHD) que permite relacionar categorías de análisis vinculadas con la agenda Setting y niveles de discurso periodístico derivados de la teoría del Newsmaking. Esta aproximación permite establecer las intencionalidades discursivas de los medios, no sólo desde la construcción social de realidad, sino también desde las rutinas periodísticas y algunos criterios de noticiabilidad (Martini, 2007).

En una matriz de Excel ${ }^{\circledR}$ 1, se recopiló la información consignada en los artículos: fecha, titular, criterio de inclusión, síntesis del texto, y las categorías de análisis de acuerdo con el modelo de las capas de cebolla de McCombs (1992) y la teoría de Newsmaking desarrollada en distintos momentos por Tuchman (1983), Verón (1987) y Shoemaker \& D. Reese (1996). De acuerdo con la estructura informativa de los periódicos en Latinoamérica (De Diego, 2017), la presente investigación estableció tres capas de análisis. Con base en la teoría de agenda Setting se incorporaron los personajes, instituciones, territorios, temas y controversias (primera capa o agenda Setter), y el interés común, marginalidad y estilos de vida (segunda capa). El Newsmaking constituye la tercera capa de análisis con los niveles discursivos: género seco, interpretación y valoración. No se consideraron los niveles de postura y exhortación debido a que no se analizaron artículos de opinión o editoriales. Las dos primeras capas de análisis hacen parte del proceso de construcción social de realidad y la tercera se ocupa de las intencionalidades narrativas de los contenidos periodísticos. La síntesis del MHD puede apreciarse en la figura 2.

\footnotetext{
1 Ver registros catalogados de la investigación en https://osf.io/scdwu/
} 


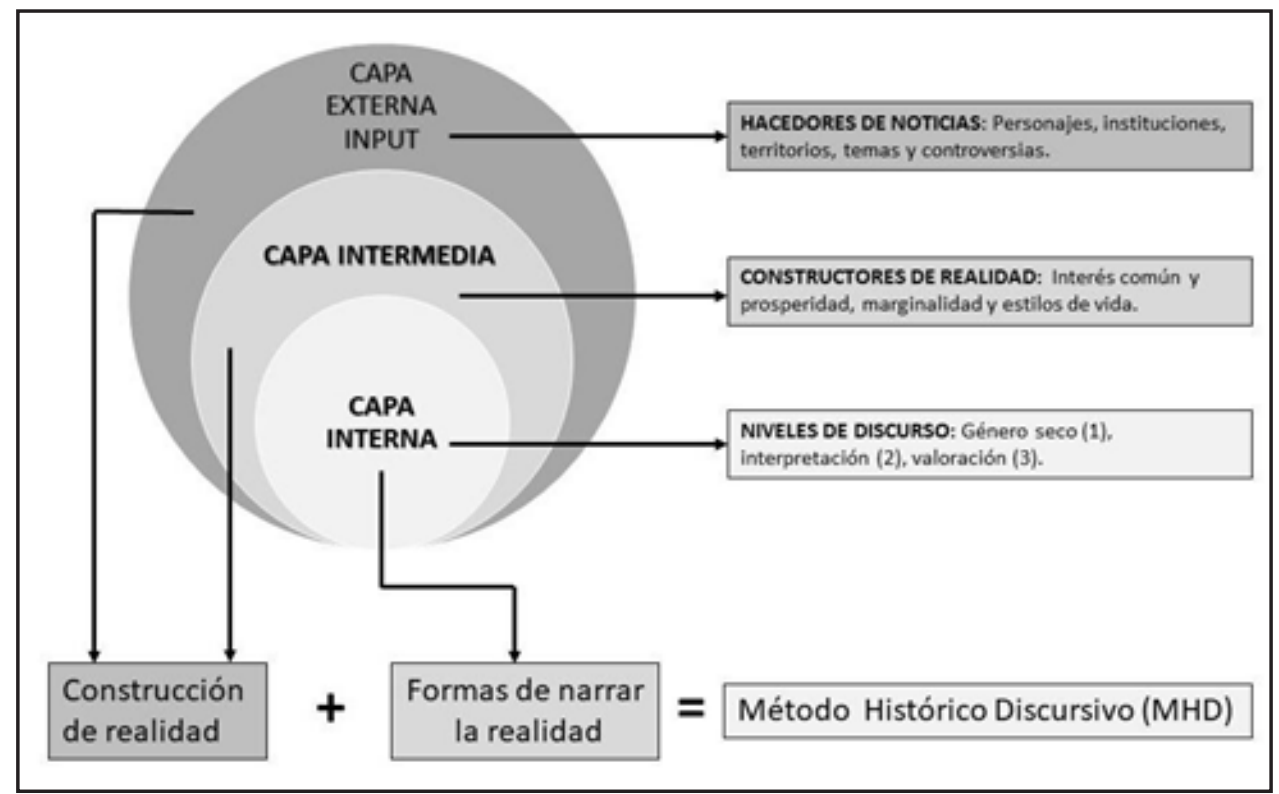

Figura 2. El Método Histórico Discursivo (MHD). El MHD se empleó para analizar la información consignada en Expreso.ec y Elpais.com.co. El método consta de tres capas de análisis (externa, intermedia, interna) en donde se articulan la construcción de realidad y las formas de narrarla.

\section{Resultados}

La agenda informativa revela tensiones entre política, sectores afectados y salud

En primer lugar, se evaluaron los aspectos contenidos en la primera capa que incluye los temas, los territorios, los personajes, las instituciones y las controversias. El análisis reveló que en ambos periódicos primó el interés por la política, los sectores afectados por la cuarentena y las medidas sanitarias (figura 2A). Allí aparecen las decisiones de los gobiernos locales en tensión con la movilidad, el comercio, el entretenimiento, el abastecimiento de las familias y la educación, así como con el manejo sanitario de la crisis (estadísticas, pruebas clínicas, tratamientos médicos, infraestructura hospitalaria).

Para Expreso.ec tuvieron más importancia los acontecimientos relacionados con los sectores afectados por la cuarentena y el sistema de salud, especialmente episodios como el manejo de los cadáveres en la ciudad en la primera semana de abril y la indisciplina social de los ciudadanos. Para Elpais.com.co la adopción de medidas desde la alcaldía de Cali y la Gobernación del Valle del Cauca ocuparon el primer lugar en cuanto a temas noticiables.

Dos visiones de ciudad desde los territorios de la información

El análisis de los territorios denota que las ciudades de Guayaquil y Cali junto con sus respectivas áreas metropolitanas fueron el foco de información (figura 2B), sin embargo, con visiones distintas sobre los hechos. En el caso de Expreso.ec, los escenarios más referenciados fueron algunos lugares públicos de carácter comercial y turístico, centros médicos y hospitalarios, algunos barrios y ciudadelas, la provincia de Guayas, los cementerios de la ciudad y el Aeropuerto José Joaquín de Olmedo. Allí tuvieron lugar sucesos relacionados con las medidas de control de las autoridades, atención de pacientes con COVID-19, entierros masivos de cadáveres y un incidente que involucró el bloqueo de la pista del aeropuerto local para impedir el aterrizaje de un vuelo humanitario de la compañía española Iberia.

Elpais.com.co tuvo la ciudad de Cali como territorio principal de los acontecimientos. El Valle del Cauca también fue referenciado como escenario de la información, así como varios países del mundo desde donde se reportaron historias de caleños en cuarentena. Del mismo modo, se reseña el municipio de Buga, donde se presentó el primer caso de COVID-19 en la región, la vía Cali-Candelaria donde está ubicada la principal central de abastos de la ciudad, y de manera puntual algunos barrios y el centro de la ciudad donde se presentaron alteraciones del orden público y violación a las medidas de cuarentena.

En este aspecto se encontró una diferencia notable entre ambos periódicos. Expreso.ec puso más énfasis en la situación de los ciudadanos en distintos barrios, ciudadelas y parroquias de Guayaquil, especialmente ante contingencias como cortes en los servicios públicos o el incidente con la recolección de cadáveres víctimas del COVID-19. Por su parte, las piezas analizadas de Elpaís. com.co reflejaron una visión más generalista de ciudad, al punto que las historias de los caleños residentes en el exterior y que pedían ayuda humanitaria para regresar a Colombia, tuvieron más despliegue (figura 3 ). 

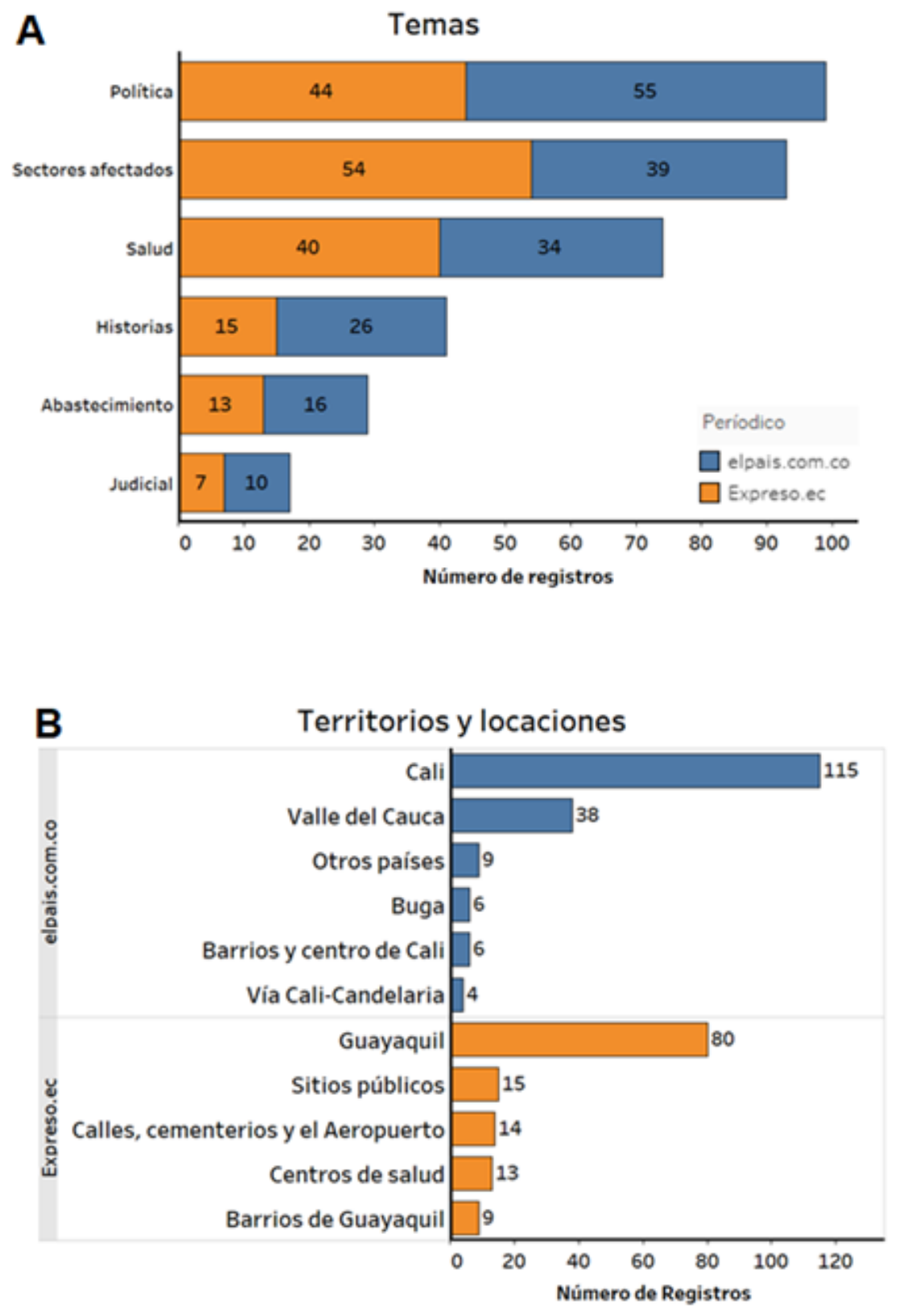

Figura 3. La política y los territorios en el foco de la información. (A) Los temas más recurrentes en la agenda informativa de los periódicos fueron la política, los sectores afectados por la pandemia y las medidas sanitarias. (B) La información de ambos medios se centró en sus respectivas ciudades y áreas metropolitanas, siendo el Expreso más específico en locaciones dentro de la ciudad. 
Los alcaldes de Guayaquil y Cali fueron el foco de la información

El análisis de la primera capa también reveló que las alcaldías de Guayaquil y Cali fueron el foco informativo de la pandemia (figura 4B). Desde allí se tomaron decisiones en materia de salud, movilidad de personas y vehículos y control de establecimientos públicos durante la cuarentena.

Para Expreso.ec también fueron importantes organismos del orden nacional como el Ministerio de Salud de Ecuador, el Comité de Operaciones de Emergencias (COE) y el Instituto Nacional de Estadísticas y Censos (INEC). En el tema de salud pública, el Hospital Los Ceibos cobró importancia por el manejo de cadáveres que se acumularon en ese lugar durante la primera semana de abril.

Para Elpais.com.co, además de la alcaldía, la gobernación del Valle del Cauca, las secretarías de Seguridad y Salud, así como la Policía Metropolitana, fueron las instituciones más destacadas en el manejo de asuntos relacionados con medidas sanitarias, control del orden público, abastecimiento de la población, atención a los más vulnerables, adecuación de espacios para atención de pacientes y cese de actividades como el fútbol.

En este sentido, para Expreso.ec primaron los políticos, incluidos dos ministros, mientras que para Elpais.com.co sobresalieron los secretarios de Salud de Cali y el Valle del Cauca.

Se resalta el protagonismo que tuvieron los alcaldes de Guayaquil, Cynthia Viteri, y de Cali, Jorge Iván Ospina (figura 4A). Por un lado, Viteri se destaca por su carácter polémico y contestatario frente a las medidas ordenadas por el gobierno nacional. El 12 abril avivó una polémica en su cuenta personal de Twitter @CynthiaViteri6 al responder al vicepresidente Otto Sonnenholzner, quien le recomendó a la mandataria a través de la misma red social "Que haga más y hable menos" (Metro Ecuador, 2020).

La respuesta de Viteri fue "cuando @ottosonnenh le diga a los familiares donde están los cuerpos perdidos de sus seres amados, ahí le respondo. A Guayaquil nadie la calla". La mandataria también usó este medio para informar, entre otras cosas, acerca de la cooperación internacional con la ciudad de Shangai para el tratamiento del COVID-19; la distribución de kits alimenticios en la ciudad, la desinfección de espacios públicos, la donación de su sueldo para atender partos debido al colapso del sistema sanitario, la creación de fondos para ayudar al sector productivo y destacar la solidaridad de empresarios y ciudadanos.

Por otro lado, Ospina es caracterizado por su insistencia en las medidas para contener la expansión del virus, dada su condición no solo como autoridad local sino como médico de profesión, y por recorrer la ciudad llamando la atención a quienes no cumplen con las medidas de aislamiento obligatorio y bioseguridad.

En su cuenta personal de Twitter @JorgelvanOspina el mandatario comentó el 12 de abril de 2020 el drama de los cadáveres en Guayaquil y dijo: "Esta situación no la queremos en Cali. Esforcémonos más, unidos, orientados con disciplina y responsabilidad" (Ospina, 2020).

También insistió en el uso adecuado de elementos de protección por parte del personal médico, las falsas noticias sobre el COVID-19, la atención de los migrantes venezolanos en Cali, la entrega de víveres en los sectores marginados de la ciudad, los riesgos de levantar el confinamiento, el llamado a que los centros comeriales realicen labores de desinfección y el rigor de mantener la cuarentena (Ver figura 4 y tabla 1).

\section{Las controversias se centraron en los personajes y los impactos de la cuarentena}

Tanto en Expreso.ec como en Elpais.com.co, los temas, personajes e instituciones fueron objeto de controversias en los 34 días de seguimiento a los portales (tabla 1). Para Expreso.ec el mayor número de controversias giró en torno a los sectores afectados por las medidas de aislamiento (ciudadanía en general, comerciantes, estudiantes y transporte público) y las posiciones de la alcaldesa de Guayaquil frente a las determinaciones del gobierno nacional.

Entre tanto, Elpais.com.co referenció principalmente las fuertes medidas adoptadas por el alcalde de Cali durante la cuarentena, y su impacto en sectores como la cultura, los espectáculos, el comercio y la movilidad de los ciudadanos. 


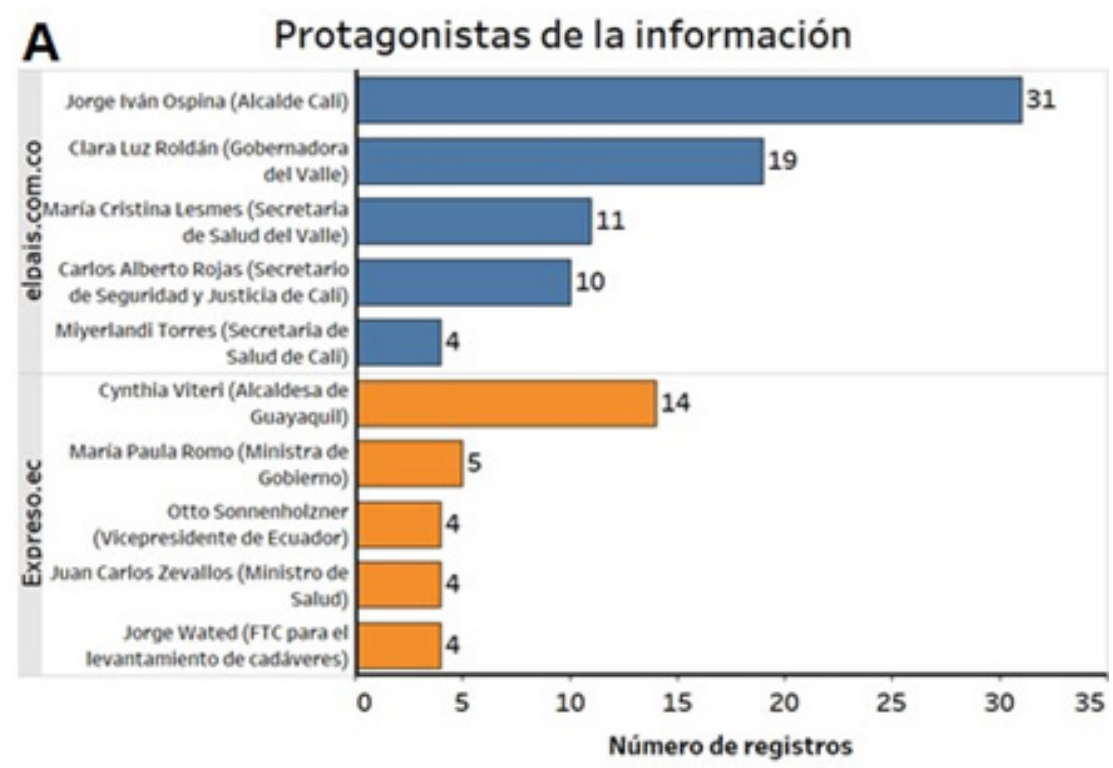

\section{Instituciones más referenciadas}

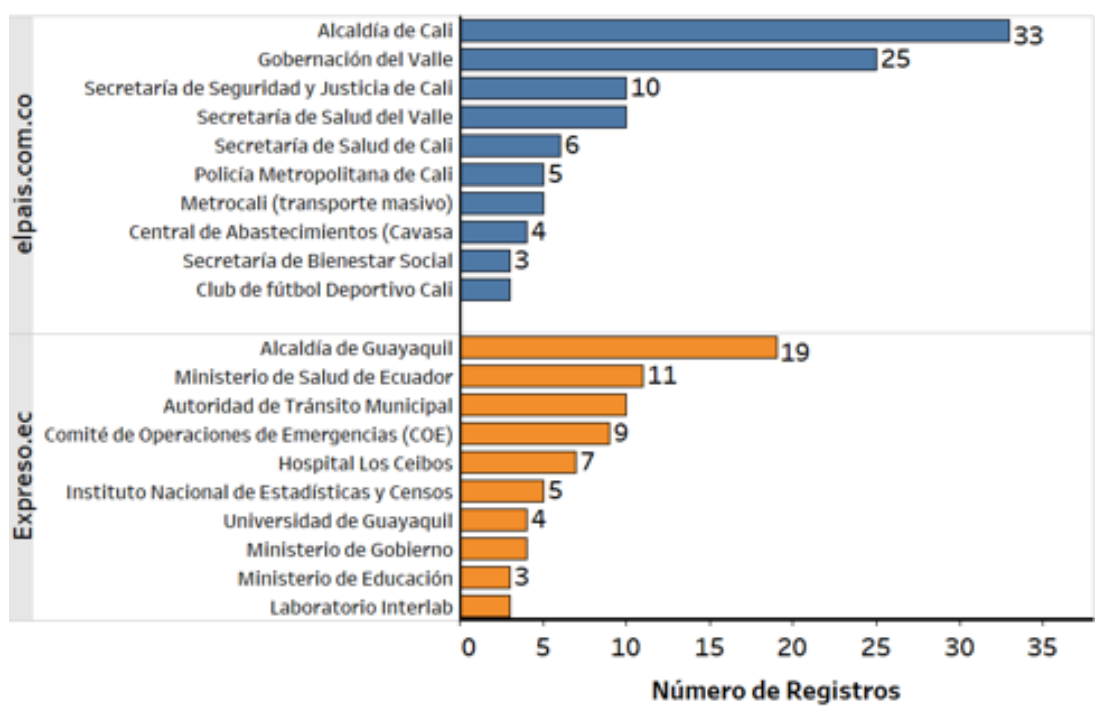

Figura 4. La información de los diarios giró en torno a las alcaldías locales y sus dirigentes. (A) Los alcaldes de Cali, Jorge Iván Ospina, y de Guayaquil, Cynthia Viteri fueron los más referenciados por los medios de comunicación, seguidos por personajes de la agenda política de la región o el país. (B) La información giró en torno a las alcaldías de Cali y Guayaquil debido a las medidas de salud y controles públicos empleados. 
Tabla 1. Resumen de los temas, personajes e instituciones donde se concentraron las controversias recogidas en la información de Expreso.ec y Elpais.com.co

\begin{tabular}{|c|c|c|c|c|}
\hline $\begin{array}{l}\text { Primera capa } \\
\text { (agenda } \\
\text { Setter) } \\
\end{array}$ & Expreso.ec & Registros & elpais.co & Registros \\
\hline \multirow[t]{6}{*}{ Temas } & Sectores afectados & 47 & Política & 48 \\
\hline & Política & 40 & Sectores afectados & 35 \\
\hline & Salud & 33 & Historias & 23 \\
\hline & Abastecimiento & 12 & Salud & 22 \\
\hline & Historias & 7 & Judicial & 10 \\
\hline & Judicial & 7 & Abastecimiento & 9 \\
\hline \multirow[t]{5}{*}{ Personajes } & $\begin{array}{l}\text { Cynthia Viteri, alcaldesa de } \\
\text { Guayaquil }\end{array}$ & 14 & $\begin{array}{l}\text { Jorge Iván Ospina, alcalde de } \\
\text { Cali }\end{array}$ & 25 \\
\hline & $\begin{array}{l}\text { Jorge Wated, encargado de } \\
\text { levantamiento de cadáveres. }\end{array}$ & 4 & $\begin{array}{l}\text { Clara Luz Roldán, gobernadora } \\
\text { del Valle }\end{array}$ & 13 \\
\hline & $\begin{array}{l}\text { María Paula Romo, ministra } \\
\text { de Gobierno }\end{array}$ & 4 & $\begin{array}{l}\text { Carlos Rojas, secretario de } \\
\text { Seguridad de Cali }\end{array}$ & 10 \\
\hline & $\begin{array}{l}\text { Otto Sonnenholzner, } \\
\text { vicepresidente de Ecuador }\end{array}$ & 3 & $\begin{array}{l}\text { María Cristina Lesmes, } \\
\text { secretaria de Salud del Valle }\end{array}$ & 10 \\
\hline & $\begin{array}{l}\text { Alexandra Ocles Padilla, } \\
\text { directora del Servicio } \\
\text { Nacional de Gestión de } \\
\text { Riesgos y Emergencias } \\
\text { (SNGRE) }\end{array}$ & 3 & $\begin{array}{l}\text { General Manuel Vásquez, } \\
\text { comandante de la Policía } \\
\text { Metropolitana de Cali }\end{array}$ & 3 \\
\hline \multirow[t]{5}{*}{ Instituciones } & Alcaldía de Guayaquil & 19 & Alcaldía de Cali & 24 \\
\hline & $\begin{array}{l}\text { Ministerio de Salud de } \\
\text { Ecuador }\end{array}$ & 9 & Gobernación del Valle del Cauca & 18 \\
\hline & $\begin{array}{l}\text { Autoridad de Tránsito } \\
\text { Municipal (ATM) }\end{array}$ & 8 & $\begin{array}{l}\text { Secretaría de Seguridad y } \\
\text { Justicia de Cali }\end{array}$ & 10 \\
\hline & $\begin{array}{l}\text { Comité de Operaciones de } \\
\text { Emergencias (COE) }\end{array}$ & 6 & $\begin{array}{l}\text { Secretaría de Salud del Valle del } \\
\text { Cauca }\end{array}$ & 9 \\
\hline & Hospital Los Ceibos & 6 & Secretaría de Salud de Cali & 5 \\
\hline
\end{tabular}




\section{El estilo de vida se acentuó con la pandemia}

El análisis de la segunda capa, que incluye las categorías de bien común, marginalidad y estilo de vida, reveló la importancia de aspectos relacionados con el estilo de vida en ambos medios (Elpais.com.co 145 registros, 80,5\% y Expreso.ec 128 registros, 73.9\%).

Lo anterior puede relacionarse con las controversias generadas por las medidas de control y la indisciplina social en la cuarentena. Por otro lado, Elpais.com.co (115 registros, 63\%) resalta un mayor número de veces la idea del bien común, comparado con el Expreso.ec (78 registros, $45 \%$ ).

No obstante, la tendencia es similar en ambos medios en cuanto a la marginalidad, asociada a cuestiones como la pobreza, el comercio informal, la calidad de la atención sanitaria a los más vulnerables y el manejo de los cadáveres por COVID-19 en los sectores más pobres de Guayaquil (figura 5A).
Los datos oficiales primaron sobre los relatos de interés humano

Finalmente, el análisis de los niveles discursivos en la tercera capa (figura 5B) denota que tanto en el Expreso.ec (120 registros, 69.3\%) como en Elpais.com.co (133 registros, $73.8 \%$ ) predomina el género seco (nivel 1), representado en los datos epidemiológicos y las medidas de los gobiernos locales en materia de control social (movilidad, cierre de establecimientos públicos, control de precios, protocolos sanitarios, y rutas de atención de pacientes). En el nivel 2 (interpretación), Expreso.ec (25 registros, 14,4\%) realizó un análisis más profundo sobre el COVID-19 consultando a expertos en distintas materias (epidemiólogos, microbiólogos, psicólogos, sociólogos y estadísticos) y entrevistas con funcionarios públicos y autoridades responsables. Por su parte, la valoración (nivel 3) presentó 32 registros (17.7\%) en Elpais.com.co y 28 registros (16.1\%) en el Expreso.eccon historias de interés humano que involucraron testimonios de pacientes, familiares de fallecidos por el virus, ciudadanos de Cali y Guayaquil en el exterior, usuarios del transporte público, y personal médico.

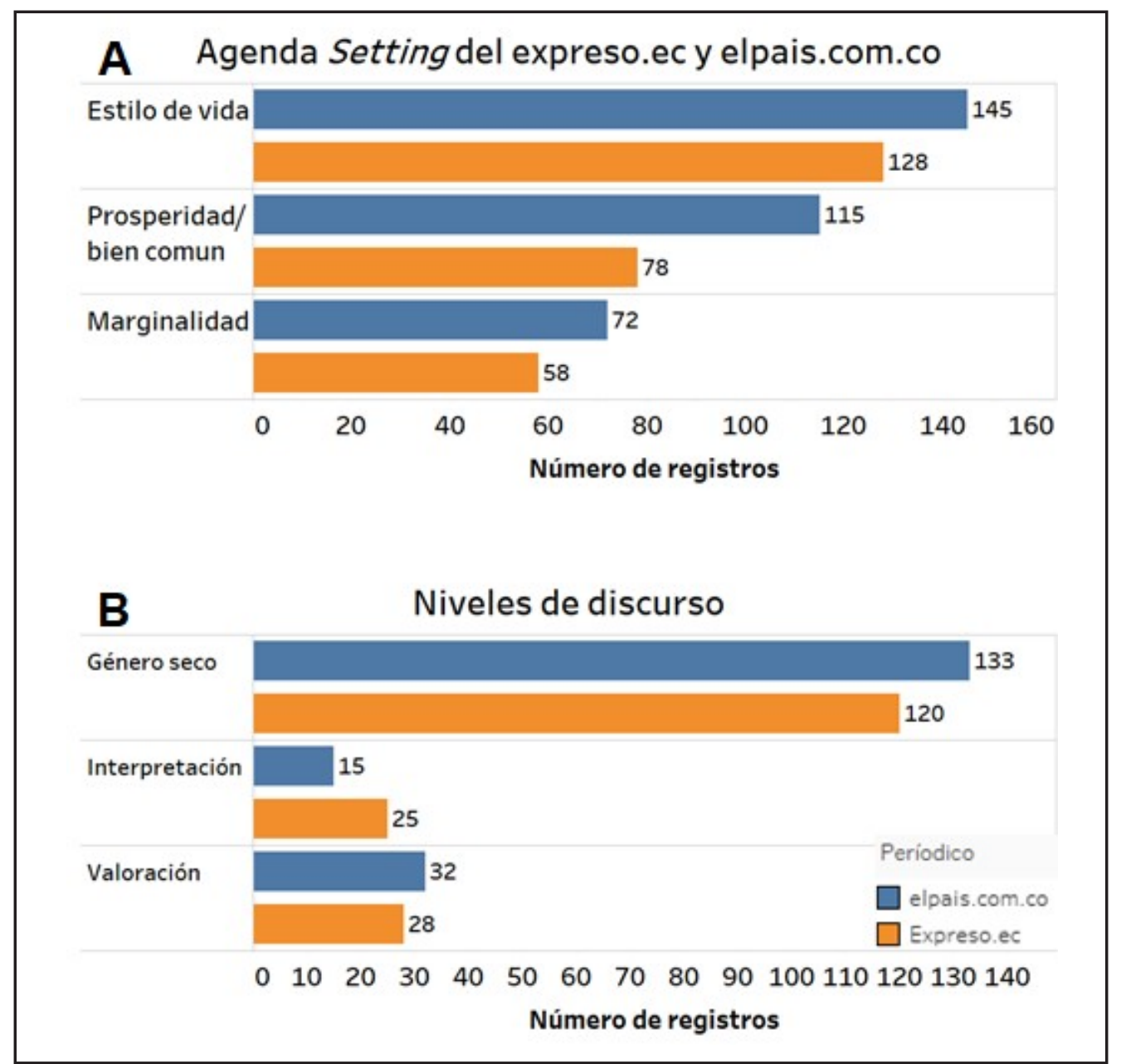

Figura 5. El estilo de vida y los datos oficiales fueron el centro informativo. (A) Factores asociados al estilo de vida como rutinas de supervivencia ("rebusque"), adquisición de bienes y servicios, movilización, entretenimiento y estudio sobresalieron en ambos medios. (B) La información sobre COVID-19 se basó principalmente en los datos epidemiológicos y las medidas de salubridad y control social tomadas por las autoridades locales (género seco). En comparación, hubo poca interpretación y valoración de los sucesos. 


\section{Discusión y conclusiones}

Los resultados revelaron las tensiones entre el ejercicio político, los efectos de la pandemia en la cotidianidad de las ciudades de Guayaquil y Cali, y las prioridades en materia de salud pública. Así mismo, se revelaron perspectivas distintas de los territorios a la luz de los énfasis en el cubrimiento informativo de los dos medios. Los alcaldes de Guayaquil y Cali emergieron como protagonistas en la mayoría de los contenidos dada su condición de autoridades, pero también por sus posiciones políticas y medidas de control. La mayoría de las controversias reveladas involucran el impacto de las medidas de aislamiento en materia de movilidad, actividades económicas, entretenimiento y educación. Por otra parte, los estilos de vida de guayaquileños y caleños fueron reflejados en los contenidos sobre las sanciones impuestas por las autoridades, la adopción de medidas de bioseguridad, las nuevas reglas en materia de movilidad, entretenimiento, deporte y educación. En lo que concierne a la tipología del discurso periodístico, tanto en el Expreso.ec como en Elpais.com.co primaron los datos e información oficial sobre el avance de la pandemia y la promulgación de decretos en el marco del aislamiento. El análisis de los acontecimientos por parte de los medios de comunicación fue reducido, de la misma manera que las historias de interés humano.

Como un reflejo de los aspectos sociales involucrados en la pandemia del COVID-19, nuestros resultados revelan la precariedad de los sistemas de salud pública en ambos países como un objeto frecuente de información. En el caso de Guayaquil fue clara la impotencia institucional para la atención de pacientes en los servicios de urgencias, la escasez de oxígeno y la disposición de cadáveres (Toranzos, 2020). Por su parte, en Cali, la falta de pruebas para el diagnóstico de COVID-19 no hizo posible un seguimiento sistemático a la expansión del virus (El País, 2020c) a finales de marzo, a pesar que durante la ventana de observación del estudio no se presentó congestión en los servicios de urgencias. En ambas ciudades también fue evidente la escasez de mascarillas, guantes y otros elementos de bioprotección. Al respecto, puede concluirse que la información, basada fundamentalmente en datos epidemiológicos y decisiones gubernamentales, no contribuyó a que los ciudadanos de Guayaquil y Cali entendieran de la mano de expertos la importancia de algunas medidas sanitarias.

Mantener el encuadre informativo (framing) (Entman, 1993) en los funcionarios públicos no contribuyó a hacer visible las condiciones de vida de los ciudadanos. No fue sólo hasta cuando comenzaron a verse los cadáveres en las calles de Guayaquil que las autoridades y la opinión pública tuvieron idea de las dimensiones que había tomado la crisis, agravada por la acumulación de cuerpos en los cuartos de los hospitales (Bazán, 2020). En Cali, mientras el alcalde y la gobernadora del Valle preparaban camas hospitalarias, a mediados de marzo continuaba el flujo de pasajeros internacionales sin control por el Aeropuerto Internacional Alfonso Bonilla Aragón (El País, 2020a). Estos son algunos elementos que permiten entender cómo Guayaquil y Cali se convirtieron en territorios con altos niveles de contagio.

Nuestro estudio denota que ambos medios de comunicación no explicaron las razones de las controversias que registraron. El cierre de establecimientos públicos y las restricciones a actividades cotidianas y de entretenimiento tanto en Guayaquil como Cali no pasaron del registro de las irregularidades. Nuevamente, el estilo de vida de los guayaquileños se hizo evidente en temas como las diligencias bancarias o la compra de víveres (Ortíz Salinas, 2020), mientras que en Cali fue más importante registrar los llamados de atención del alcalde a los ciudadanos que violaban las medidas sanitarias (El País, 2020b).

En los contenidos no siempre se establecieron puentes entre los problemas de marginalidad, asociados a factores de pobreza y carencia de servicios básicos, y la construcción de soluciones. Colombia y Ecuador hacen parte de una región con fuertes debilidades institucionales (Malamud, 2020). Sería conveniente que los medios realizaran apuestas informativas más contextualizadas. Esto implica analizar problemas estructurales de las naciones como la corrupción, el desgreño administrativo en los servicios públicos y otros aspectos que fueron motivo de protesta social durante 2019 en países como Chile, Bolivia, Ecuador y Colombia.

La amplia diferencia en el número de registros entre los discursos de nivel 1 (género seco) en comparación con la interpretación (nivel 2) y la valoración (nivel 3) reflejan el interés de los medios por los datos oficiales más que por el análisis y la explicación de los acontecimientos sobre los que se informa. En este sentido, nuestro estudio permite inferir que el origen de la información en ambos periódicos fueron los boletines oficiales de los gobiernos locales, y no tanto el reporterismo o el contraste con otras fuentes. Sería interesante establecer el interés o la capacidad de los medios para desplazar durante la pandemia equipos de reporteros en búsqueda de historias.

Una limitación es que nuestro análisis no permitió vislumbrar la forma como los periodistas planearon sus historias y cubrieron los hechos. Futuros estudios podrían considerar entrevistas a periodistas y editores para conocer el impacto en la calidad informativa 
sobre la pandemia derivado de de la reducción de puestos de trabajo en las salas de redacción y la falta de especialización en temas de salud por parte de los encargadosde cubrir esta fuente. También es relevante emplear un efoque multidisciplinar para estudiar la percepción del riesgo sanitario de quienes estuvieron realizando tareas de reporterismo sobre el COVID-19. Asimismo, estudiar las representaciones sociales que deja el COVID-19 en distintos tipos de público expuestos a la información de los medios.

En conclusión, para Expreso.ec y Elpais.com. co el cubrimiento de la pandemia cambió los titulares, pasando de la protesta social en 2019 , a una radiografía de dos ciudades a las que el COVID-19 mostró con todas sus debilidades institucionales. Las agendas mediáticas reactivas implementadas por Expreso.ec y Elpais. com.co durante la presente pandemia, recuerdan los partes de guerra, en donde prima el número de muertos. En ese pedazo de realidad que revelaron los artículos analizados se advierten no sólo los cambios sociales generados por la pandemia, sino aquello que permanece en el imaginario social, y que entra en conflicto con las medidas gubernamentales. Los vacíos en el cubrimiento informativo durante la pandemia del COVID-19 invitan a realizar un periodismo más analítico en conjunto con una mejor preparación del equipo humano detrás de la noticia.

\section{Referencias bibliográficas}

Álvarez, V. H. (2010). Análisis de la pandemia de Influenza A H1N1. Comparativo 2009-2010. Recuperado el 3 de abril de 2020 del website: https:// bit.ly/3clrfih

Aruguete, N. (2017). Agenda building. Revisión de la literatura sobre el proceso de construcción de la agenda mediática. Signo y Pensamiento, 36(70), 36. https://doi.org/10.11144/Javeriana.syp36-70.abrl

Bastenier, M. A. (2001). El blanco móvil. Curso de periodismo. Madrid, España: Santillana.

Bazán, C. (2020, April 6). Coronavirus: "Hay cuerpos enterrándose en bolsas." Expreso.ec. Recuperado el 13 de mayo de 2020 del website: https://bit. ly/2T93bYw

Berger, P., \& Luckmann, T. (2001). La construcción social de la realidad. Buenos Aires, Argentina: Amorrortu editores.

Califano, B. (2015). Los medios de comunicación, las noticias y su influencia sobre el sistema político. Revista Mexicana de Opinión Pública, 19, 6179. https://doi.org/10.1016/j.rmop.2015.02.001

Camus, A. (2016). La peste. México D.F, México: Editores Mexicanos Unidos.

Carvajal Estupiñán, J. F., Martínez Martín, A. F., Meléndez Álvarez, B. F., \& Manrique, F. G. (2006). La pandemia de gripa de 1918 en Bogotá. Aproximación históricoepidemiológica. Perspectiva Salud Enfermedad, 13(1), 19-32.

Charaudeau, P. (2003). El discurso de la información. La construcción del espejo social. Barcelona, España: Gedisa.

Colón, C., De Cuneo, M., De las Casas, F. B., Cortés, H., Díaz del Castillo, B., Núñez Cabeza de Vaca, A., ... Pigafetta, A. (2005). Cronistas de Indias: antología. Bogotá, Colombia: Panamericana Editorial.

Cordero del Campillo, M. (2001). Las grandes epidemias en la América colonial. Archivos de Zootecnia, 50(192), 9.

Coronado Robles, R., Catalán-Matamoros, D., \& Martínez González, E. (2016). La gripe A(H1N1) en prensa. Revista Española de Comunicación en Salud, 2, 32-45. https://doi.org/10.20318/recs.2016.3403

De Diego, J. (2017). El Periódico como institución política. Claves teóricas para comprender las luchas simbólicas del discurso informativo en los grandes diarios de América Latina. Intersticios Sociales, 14, 5-34.

Eicher, V., \& Bangerter, A. (2015). Social representations of infectious diseases. In G. Sammut, E. Andreouli, G. Gaskell, \& J. Valsiner (Eds.), The Cambridge Handbook of Social Representations (pp. 385396). Cambridge: Cambridge University Press. doi:10.1017/CBO9781107323650.031

El País, R. (2020a, March 9). "Ingresó sin ningún tipo de control por el Aeropuerto": Alcalde de Buga sobre paciente con coronavirus. Elpais.com.co. Recuperado de: https://bit.ly/2KyEe44

El País, R. (2020b, March 20). Ospina sorprendió a varios extranjeros bailando en la calle y no en aislamiento. Elpais.com.co. Recuperado de: https://bit. ly/2RZSsir 
El País, R. (2020c, March 29). "Solicitamos al INS resultados de pruebas para entender el brote en Cali": Ospina tras nueva muerte. Elpais.com.co. Recuperado de: https://bit.ly/3bBPGI5

El País, R. (2020d, April 13). Minsalud reporta 76 casos nuevos de Covid-19 en Colombia; muertes aumentan a 112. El País.com.co. Recuperado de: https://bit. ly/2xK1fy9

El Relator. (1918, Diciembre 18). La gripa. El Relator.

El Tiempo, R. (2009, Abril 28). Casos sospechosos de ser gripa porcina subieron de 12 a 42 en Colombia, cuatro de ellos generan preocupación. El Tiempo. Recuperado de: https://bit.ly/2WMZ7j7

El Tiempo, R. política. (2020, March 30). El 90\% de los colombianos cree que es posible contraer coronavirus. El Tiempo. Recuperado de: https://bit. $\mid \mathrm{y} / 2 \mathrm{VhPOq|}$

Entman, R. M. (1993). Framing: toward clarification of a fractured paradigm. Journal of Communication, $43,51-58$.

Eslava Albarracín, D. G., \& Puntel de Almeida, M. C. (2002). Representaciones sociales la salud y la enfermedad: investigando el estado del arte. Ciencia y Enfermería, 8(2), 59-72. https://doi. org/10.4067/S0717-95532002000200007

Funk, M. J., \& McCombs, M. (2017). Strangers on a Theoretical Train: Inter-media agenda setting, community structure, and local news coverage. Journalism Studies, 18(7), 845-865. https://doi.or $\mathrm{g} / 10.1080 / 1461670 X .2015 .1099460$

Garabato González, S. (2002). EI VIH/SIDA en los medios de comunicación social escritos: Análisis cuantitativo de una muestra de periódicos. Trabajo Social Hoy, (37), 131-141.

García Gual, C. (2012). Apuntes sobre la muerte de Alejandro Magno en algunos textos hispánicos del Medioevo. En R. Alemany Ferrer \& F. Chico Rico (Eds.), Literaturas ibéricas medievales comparadas (pp. 237-246). Alicante, España: Universidad de Alicante.

Guzmán, M., \& Martínez Prediger, C. (2010). Agenda Setting - Agenda Cutting - Agenda Surfing: una aproximación a las actuales aplicaciones de la teoría. En L. Luchessi (Ed.), Nuevos escenarios detrás de las noticias. Buenos Aires, Argentina: La Crujía.
Idoiaga Mondragon, N., Gil de Montes, L., \& Valencia, J. (2017). Understanding an Ebola Outbreak: Social representations of emerging infectious diseases. Journal of Health Psychology, 22(7), 951-960. https://doi.org/10.1177/1359105315620294

Idoiaga Mondragon, N., Gil de Montes, L., \& Valencia, J. (2018). Understanding the emergence of infectious diseases: Social representations and mass media. Communication \& Society, 31(3), 319-330.

Johns Hopkins University. (2020). COVID-19 Dashboard by the Center for Systems Science and Engineering (CSSE) at Johns Hopkins University (JHU). Recuperado de: https://bit. ly/2A9aBVs

La Rosa, M. J., \& Mejía, G. (2017). Historia concisa de Colombia. Bogotá, Colombia: Penguin Random House Grupo Editorial, S.A.S.

Malamud, C. (2020). El COVID-19 en América Latina: desafíos políticos, retos para los sistemas sanitarios e incertidumbre económica. Recuperado de: https://bit.ly/2y6KEoD

Manrique, F. G., Martínez, A. F., Meléndez, B. F., \& Ospina, J. M. (2009). La pandemia de gripe de 1918-1919 en Bogotá y Boyacá, 91 años después. Infectio, 13(3), 182-191. https://doi.org/10.1016/ s0123-9392(09)70148-1

Martín Lahuerta, M. (2006). Visión social del VIH/SIDA. Metas de Enfermería, 9(8), 10-16.

Martín, N. L., Doblas, M. L., Cerdà, J. C. M., \& Danet, A. (2014). La difusión de las campañas de prevención del VIH en la prensa escrita española. Revista de Comunicación y Salud, 4(1), 5-17.

Martini, S. (2007). Periodismo, noticia y noticiabilidad. Bogotá, Colombia: Grupo Editorial Norma.

McCombs, M. (2015). Agenda Setting, Media Effects on. En International Encyclopedia of the Social \& Behavioral Sciences (pp. 351-356). Oxford: Elsevier. https://doi.org/10.1016/b978-0-08-0970868.95007-4

McCombs, M. \& Shaw, D. L. (1972). The Agenda-Setting Function of Mass Media. Public Opinion Quarterly, 36(2), 176. https://doi.org/10.1086/267990

McCombs, M. (1992). Explorers and Surveyors: Expanding Strategies for Agenda-Setting Research. 
Journalism Quarterly, 69(4), 813-824. ttps://doi. org/10.1177/107769909206900402

Metro Ecuador. (2020). Acaban en Twitter a Viteri y Sonnenholzner por su pelea. Metroecuador.com. ec, Recuperado el 18 de junio de 2020 del website: https://bit.ly/2YLBoQ5

Ministerio de Salud deEcuador. (2020). Comportamiento de casos COVID-19, según resultados de muestras PCR en el Ecuador. Recuperado de: https://tabsoft.co/2YUnjkM

Mondragón Pérez, L., Hermelin, D., \& Moreno Londoño, J. (2013). La gripa H1N1 y los noticieros de tv en Colombia: entre las representaciones del riesgo y las resonancias de imaginarios. Disertaciones: Anuario Electrónico de Estudios En Comunicación Social, 6(2), 8. https://doi. org/10.12804/disertaciones.v6i2.4392

Muñoz-Sanz, A. (2006). La gripe de Cristóbal Colón. Hipótesis sobre una catástrofe ecológica. Enfermedades Infecciosas y Microbiologia Clinica, 24(5), 326-334. https://doi. org/10.1157/13089669

OMS. (2020). Alocución de apertura del Director General de la OMS en la rueda de prensa sobre la COVID-19 celebrada el 11 de marzo de 2020. Recuperado de: https://bit.ly/2z4vro9

OPS. (2009). Ecuador: 73 casos confirmados de Influenza A (H1N1). Recuperado el 9 de mayo de 2020 del Website https://bit.ly/2xQRBdc

Ortíz Salinas, E. (2020, March 18). Guayaquil rompe normas en medio de la emergencia sanitaria. Expreso.ec. Recuperado de: https://bit.ly/2xNCzFf

Ospina, J. I. (2020, abril 12). Esta situación no la queremos en Cali. Esforcémonos más, unidos, orientados con disciplina y responsabilidad: https://bit.ly/3iam6x7 [Twitter post]. Recuperado de: https://twitter.com/JorgelvanOspina

Rodas Chaves, G. (2015). Historia de la "gripe española" que llegó a Quito en 1918. Recuperado de: https://bit.ly/3dvV1Bi

Rodas Chaves, G. (2018, April 15). Cómo se combatió la "gripe española" en Ecuador. El Comercio. Recuperado de: https://bit.ly/3boov2u

Salgado Ramos, J., Duro Mota, E., López Moyano, A. J., \& Muñoz-Delgado Buchó, L. M. (2005). La salud y los medios de comunicación. Atencion Primaria, 36(1), 50. https://doi.org/10.1157/13075932

Serrano Villalobos, O. (2018). Comunicación y salud. Communication Papers, 7(13), 267. https://doi. org/10.33115/udg_bib/cp.v7i13.21997

Shoemaker, P. J., \& D. Reese, S. (1996). Mediating the message. Theories of influences on Mass Media Content. New York, United States: Longman Group.

Singer, D. R. J. (2020). A new pandemic out of China: the Wuhan 2019-nCoV coronavirus syndrome. Health Policy and Technology, 9(1), 1-2. https://doi. org/10.1016/j.hlpt.2020.02.001

Stoian, A. M. (2019). Education, Social and Media Communication. Revista de Științe Politice: Revue des Sciences Politiques, 62, 125-135.

Toral Cáceres, A., Rodríguez Bajaña, Y., \& Clery Aguirre, C. (2014). Influenza A H1N1: reporte de un caso. Medicina, 18(2), 95-99.

Toranzos, M. (2020, April 2). Coronavirus: El vía crucis por conseguir un tanque de oxígeno. Expreso.ec. Recuperado de: https://bit.ly/2Z7xbl4

Tuchman, G. (1983). La producción de la noticia. Estudio sobre la construcción de la realidad. Barcelona, España: Editorial Gustavo Gili.

Verón, E. (1987). Construir el acontecimiento. Los medios de Comunicación masiva y el accidente en la central nuclear de Three Mile Island. Buenos Aires, Argentina: Gedisa. 